Case Reports in
Gastroenterology
Case Rep Gastroenterol 2021;15:389-394

DOI: $10.1159 / 000513146$

Published online: March 18, 2021 (c) 2021 The Author(s)

Published by S. Karger AG, Basel www.karger.com/crg

This article is licensed under the Creative Commons Attribution-NonCommercial 4.0 International License (CC BY-NC) (http://www.karger.com/Services/OpenAccessLicense). Usage and distribution for commercial purposes requires written permission.

\title{
Successful Montelukast Treatment in an Infant with Steroid-Resistant Eosinophilic Colitis
}

\author{
Nai-Wei Wang ${ }^{a}$ Hsuan Hsieh ${ }^{b}$ Yao-Jong Yang ${ }^{b}$ \\ aHull York Medical School, Allam Medical Building, University of Hull, Hull, UK; \\ ${ }^{b}$ Department of Pediatrics, National Cheng Kung University Hospital, Medical College, \\ National Cheng Kung University, Tainan, Taiwan
}

\section{Keywords}

Eosinophilic colitis · Montelukast · Steroid-sparing therapy · Diarrhea

\begin{abstract}
Eosinophilic colitis (EC) belongs to a group of idiopathic diseases called eosinophilic gastrointestinal disorders, which are characterized by eosinophil-predominant inflammation in the gastrointestinal tract. Corticosteroids is the first-line pharmacotherapy for EC refractory to diet therapy. We report an infant with steroid-resistant EC, who successfully returned to a healthy growth trajectory under the combined therapy of montelukast and ketotifen. An 8-month-old boy presented with bloody diarrhea, anemia, and failure to thrive (FTT) that started 6 days after birth. The patient has no known allergies. A trial of elementary diet was unsuccessful. The results of several stool cultures were unremarkable. Similarly, lower gastrointestinal series failed to identify anything significant. At 3 months of age, an esophagogastroduodenoscopy with biopsies from the distal duodenum and proximal jejunum were unremarkable. The diarrhea and FTT persisted. A rectosigmoidoscopy with biopsies was performed; the results led to the diagnosis of EC at 5 months of age. Oral prednisolone $1 \mathrm{mg} / \mathrm{kg} /$ day was prescribed; however, 3 months into the treatment, persistent bloody diarrhea and FTT were still noted. Montelukast and ketotifen were added, after which diarrhea and weight gain started to improve. Prednisolone and montelukast/ketotifen were tapered off 6 months after. He remains symptom free and has normal growth and development in a 5-year follow-up.
\end{abstract}




\section{Case Reports in Gastroenterology}

\begin{tabular}{l|l}
\hline Case Rep Gastroenterol 2021;15:389-394 \\
\hline DOI: 10.1159/000513146 & $\begin{array}{l}\text { @ 2021 The Author(s). Published by S. Karger AG, Basel } \\
\text { www.karger.com/crg }\end{array}$ \\
\hline
\end{tabular}

Wang et al.: Successful Montelukast Treatment in an Infant with Steroid-Resistant Eosinophilic Colitis

\section{Introduction}

Primary eosinophilic colitis (EC) is part of a spectrum of diseases called eosinophilic gastrointestinal diseases (EGID) [1]. EC is a rare disease that has been increasingly recognized in the recent decades [2]. It is characterized by abnormally high quantities of eosinophil infiltration in the colon in the absence of other causes of eosinophilia [3]. Primary EC can be associated with other atopic conditions; for instance, $80 \%$ of patients with EGID have concomitant atopic disease and $62 \%$ have specific food allergy [4]. The pathogenesis of EC remains to be elucidated. The increase in eosinophil infiltration seems to be triggered by the combination of dysbiosis, genetic predisposition, and allergens [5].

Clinical presentation of EC depends on the layer of intestine involved [6]. Disease predominantly affecting the mucosa is associated with malabsorption, diarrhea, and protein-losing enteropathy. Serosal-predominant diseases cause eosinophilic ascites. Transmural diseases cause colonic wall thickening and intestinal obstruction. There is a bimodal age distribution in presentation ranging from acute self-limited bloody diarrhea in infancy to chronic colitis with abdominal pain and diarrhea in adolescence [5]. In infants, eosinophilic proctocolitis is classically associated with the allergic reactions to the proteins in milk or soy [7]. Aside from the common occurrence of anemia secondary to bloody diarrhea, the infant is usually healthy and has normal growth trajectory [6].

Diagnosis of EC is supported by nonspecific GI symptoms, evidence of increased eosinophils in the biopsy specimens of the GI tract, and exclusion of other causes of eosinophilia [8]. Esophagogastroduodenoscopy (EGD) findings are unremarkable in most cases; however, EGD may reveal nonspecific lesions, such as patchy erythema, loss of vascularity, and aphthous ulceration. Histologic examination typically shows preserved mucosal architecture with focal aggregates of eosinophils in the laminal propria, crypt epithelium, and muscularis mucosa [5]. Because patchy disease is common, biopsy is recommended even with normal endoscopy findings.

There is no standard treatment regime for EC. The majority of the evidence supporting the current treatment options is based on case reports. Dietary therapies, such as elimination diet and amino acid-based elemental diet, have variable success [9]. Glucocorticoids are the mainstay pharmacotherapy. Other drugs also used in the treatment of EC include montelukast, ketotifen, cromoglycate, suplatast tosilate, and mycophenolate mofetil; all with varying success in achieving remission [3]. We report a case of an infant with steroid-resistant EC, who successfully returned to a healthy growth trajectory under the combined therapy of montelukast and ketotifen.

\section{Case Report}

An 8-month-old boy with a history of EC was admitted to the hospital for management of severe anemia that was detected in a regular follow-up with the pediatric gastroenterologist. The patient has had a history of chronic blood-tinged diarrhea since the neonatal period, which has resulted in anemia and failure to thrive. The patient has been on total parenteral nutrition since 1 month of age and fed with extensive hydrolysate formula after birth. Other past medical history includes neonatal seizure and right inguinal hernia. The patient has no known allergies.

\section{Karger'=}




\section{Case Reports in Gastroenterology}

Case Rep Gastroenterol 2021;15:389-394 DOI: 10.1159/000513146

c) 2021 The Author(s). Published by S. Karger AG, Basel www.karger.com/crg

Wang et al.: Successful Montelukast Treatment in an Infant with Steroid-Resistant Eosinophilic Colitis

The first episode of blood-tinged diarrhea was noted 6 days after birth, presenting along with ileus. Necrotizing enterocolitis was suspected, the patient was put on NPO and given ampicillin/sulbactam, amikacin, and metronidazole; symptoms resolved after a few days, but diarrhea relapsed about 3 weeks later. A trial of elementary diet was unsuccessful. At around 1 month of age, another episode of blood-tinged diarrhea was noted, along with weight loss, abdominal distension, and anemia. Necrotizing enterocolitis was again suspected, and the patient was treated with the appropriate antibiotics and put on total parenteral nutrition with lipofundin. Blood and stool culture results were negative. Stool analysis and culture were obtained with each episode of diarrhea to investigate for evidence of infection and maldigestion (stool-reducing substance, stool fat). Aside from the positive fecal occult blood, all other results were unremarkable. In addition, a lower GI series was performed but failed to identify anything significant. In light of the chronic, recurrent diarrhea and the negative investigation results, an EGD was performed at around 3 months of age. Biopsies were obtained from the proximal and distal duodenum. Both endoscopic findings and biopsy results were unremarkable.

After 5 months of recurrent blood-tinged diarrhea, a rectosigmoidoscopy was performed. The endoscopy revealed continuous erythematous erosion and shallow ulceration along the colon, with the rectum being spared. Biopsies were randomly obtained from the colon at 3 different locations; all of them showed dense infiltration of eosinophils ( $>60$ cells/HPF) in the lamina propria, muscularis mucosae, and submucosa (Fig. 1a). The clinical picture was in keeping with EC compatible with allergic colitis. Oral prednisolone solution $1 \mathrm{mg} / \mathrm{kg} /$ day was prescribed, and formula was changed to Nutramigen. Intermittent diarrhea was still noted; however, the stool was more solid. Immunodeficiency survey showed hypogammaglobulinemia $(\mathrm{A} / \mathrm{G}=3.5 / 1.7)$ and relatively low $\mathrm{T}$-cell ratio (CD3 31.6\%, CD4 17.7\%), possibly secondary to malnutrition.

During a regular follow-up with the pediatric gastroenterologist, severe anemia (Hb, 5.6 $\mathrm{g} / \mathrm{dL}$ ) was noted. Pack red blood cell transfusion was given in an outpatient setting; however, anemia persisted. Further investigation revealed positive fecal occult blood and iron deficiency (total iron $15 \mu \mathrm{g} / \mathrm{dL}$, transferrin saturation $4.6 \%$, ferritin $13.4 \mathrm{ng} / \mathrm{mL}$ ); the patient was admitted to the hospital for management. Meanwhile, the patient was still experiencing intermittent blood-tinged diarrhea and poor weight gain. Montelukast (5 mg QD) and ketotifen (0.33 mg QD) were added to the treatment. Symptoms started to improve, and prednisolone was tapered off in 7 months. The blood-tinged diarrhea gradually improved, and the body weight gain achieved the ideal growth even after stopping the oral medications (Fig. 2). Subsequent colonoscopy still revealed patchy erythematous lesions in the colon, however, the eosinophils infiltration became less severe on the colonic biopsies (Fig. 1b). This patient remains well in a 5-year follow-up.

\section{Discussion/Conclusion}

Montelukast is a selective and competitive antagonist of cysteinyl leukotriene receptor (Cys-LT1), which blocks the action of leukotriene C4, D4, E4. Leukotrienes are lipid mediators released by eosinophils which function to increase vascular permeability, increase mucus secretion, and stimulate smooth muscle contraction. In addition, they act as potent and selective chemoattractant for eosinophils and stimulate eosinophil proliferation in the bone marrow $[10,11]$. It is a well-tolerated drug, with the commonest reported adverse effects being

\section{Karger's'}




\section{Case Reports in Gastroenterology}

\begin{tabular}{l|l}
\hline Case Rep Gastroenterol 2021;15:389-394 \\
\hline DOI: 10.1159/000513146 & $\begin{array}{l}\text { ○ 2021 The Author(s). Published by S. Karger AG, Basel } \\
\text { www.karger.com/crg }\end{array}$ \\
\hline
\end{tabular}

Wang et al.: Successful Montelukast Treatment in an Infant with Steroid-Resistant Eosinophilic Colitis

headache, asthma, and upper respiratory tract infection; these were reported at a rate not statistically different from placebo. A rare adverse effect of montelukast is Churg-Strauss syndrome [12].

There has been a growing body of evidence supporting the effectiveness of montelukast as a steroid-sparing therapy for eosinophilic gastroenteritis [11,13-16]. However, the effectiveness of montelukast as a treatment for EC still remains to be evaluated. To our best knowledge, Ibis et al. [17] reported the only evidence that describes a remission of EC with montelukast; however, montelukast was given in combination with budesonide in a patient with Waldenstrom macroglobulinemia.

Ketotifen is a second-generation antihistamine that functions in stabilizing mast cells and preventing mast cell degranulation [2]. Similar to montelukast, it is a promising steroid-sparing therapy for EGID; however, its effectiveness as a monotherapy or combination therapy in EC still needs to be evaluated.

In this report, our patient successfully tapered off prednisolone after the addition of montelukast and ketotifen. The patient still experiences short-term relapses of diarrhea; however, these episodes were less severe. More importantly, after the addition of montelukast and ketotifen to the medication regime, the patient's growth trajectory shifted to above the 3rd percentile within 4 months. Further growth to above the 25 th percentile was achieved in another 6 months. The growth trajectory has been relatively stable since the addition of montelukast and ketotifen, ranging between 15th and 25th percentiles.

In conclusion, primary EC is a rare disease characterized by idiopathic infiltration of eosinophils in the colon. There is no standard treatment for EC; elimination diet and glucocorticoids are the common first-line therapies. In this case report, the combined treatment of montelukast and ketotifen was successful in alleviating the symptoms and inducing remissions in an infant with EC. Moreover, it corrected the failure to thrive caused by EC.

\section{Statement of Ethics}

The parents of the patient have given their written informed consent to publish this case (including publication of images) in Case Reports in Gastroenterology.

\section{Conflict of Interest Statement}

The authors have no conflicts of interest to declare.

\section{Funding Sources}

No funding was obtained for this case report.

\section{Karger' $=$}




\section{Case Reports in Gastroenterology}

\begin{tabular}{l|l}
\hline Case Rep Gastroenterol 2021;15:389-394 \\
\hline DOI: 10.1159/000513146 & $\begin{array}{l}\text { ○ 2021 The Author(s). Published by S. Karger AG, Basel } \\
\text { www.karger.com/crg }\end{array}$ \\
\hline
\end{tabular}

Wang et al.: Successful Montelukast Treatment in an Infant with Steroid-Resistant Eosinophilic Colitis

\section{Author Contributions}

N.-W. Wang was involved in the clinical data preparation and in drafting the manuscript; $\mathrm{H}$. Hsieh was involved in the assistance of data preparation and in the drawing of figures; Y.-J. Yang contributed to the interpretation of data, editing, and final approval of the manuscript.

\section{References}

1 Rothenberg ME. Eosinophilic gastrointestinal disorders (EGID). J Allergy Clin Immunol. 2004 Jan;113(1):1128.

2 Alfadda AA, Storr MA, Shaffer EA. Eosinophilic colitis: an update on pathophysiology and treatment. Br Med Bull. 2011;100(1):59-72.

3 Ridolo E, Melli V, De' Angelis G, Martignago I. Eosinophilic disorders of the gastro-intestinal tract: an update. Clin Mol Allergy. 2016 Dec;14(1):17.

4 Guajardo JR, Plotnick LM, Fende JM, Collins MH, Putnam PE, Rothenberg ME. Eosinophil-associated gastrointestinal disorders: a world-wide-web based registry. J Pediatr. 2002 Oct;141(4):576-81.

5 Impellizzeri G, Marasco G, Eusebi LH, Salfi N, Bazzoli F, Zagari RM. Eosinophilic colitis: A clinical review. Dig Liver Dis. 2019 Jun;51(6):769-73.

6 Alfadda AA, Storr MA, Shaffer EA. Eosinophilic colitis: epidemiology, clinical features, and current management. Therap Adv Gastroenterol. 2011 Sep;4(5):301-9.

7 Lake AM. Food-induced eosinophilic proctocolitis. J Pediatr Gastroenterol Nutr. 2000;30 Suppl:S58-60.

8 Alhmoud T, Hanson JA, Parasher G. Eosinophilic Gastroenteritis: An Underdiagnosed Condition. Dig Dis Sci. 2016 Sep;61(9):2585-92.

9 Lucendo AJ, Serrano-Montalbán B, Arias Á, Redondo O, Tenias JM. Efficacy of Dietary Treatment for Inducing Disease Remission in Eosinophilic Gastroenteritis. J Pediatr Gastroenterol Nutr. 2015 Jul;61(1):56-64.

10 Friesen CA, Kearns GL, Andre L, Neustrom M, Roberts CC, Abdel-Rahman SM. Clinical efficacy and pharmacokinetics of montelukast in dyspeptic children with duodenal eosinophilia. J Pediatr Gastroenterol Nutr. 2004 Mar;38(3):343-51.

11 Schwartz AD, Pardi SD, Murray AJ. The use of montelukast as a steroid sparing agent for recurrent eosinophilic gastroenteritis. Am J Gastroenterol. 2000;95(9):2605-2605.

12 Price D. Tolerability of montelukast. Drugs. 2000;59 Suppl 1:35-42.

13 Tien FM, Wu JF, Jeng YM, Hsu HY, Ni YH, Chang MH, et al. Clinical features and treatment responses of children with eosinophilic gastroenteritis. Pediatr Neonatol. 2011 Oct;52(5):272-8.

14 De Maeyer N, Kochuyt AM, Van Moerkercke W, Hiele M. Montelukast as a treatment modality for eosinophilic gastroenteritis. Acta Gastroenterol Belg. 2011 Dec;74(4):570-5.

15 Vithayasai N, Jennuvat S, Lertsatit A. Eosinophilic gastrointestinal disease: analysis of sixteen cases from ten years experience in Thailand. J Med Assoc Thai. 2011 Aug;94 Suppl 3:S41-8.

16 Quack I, Sellin L, Buchner NJ, Theegarten D, Rump LC, Henning BF. Eosinophilic gastroenteritis in a young girl-long term remission under Montelukast. BMC Gastroenterol. 2005 Jul;5(1):24.

17 Ibis M, Beyazit Y, Sayilir A, Suvak B, Torun S, Kekilli M. Successful treatment of eosinophilic colitis by montelukast sodium plus budesonide in a patient with Waldenstrom macroglobulinemia. J Crohn's Colitis. 2011 Jun;5(3):277-8. 


\section{Case Reports in Gastroenterology}
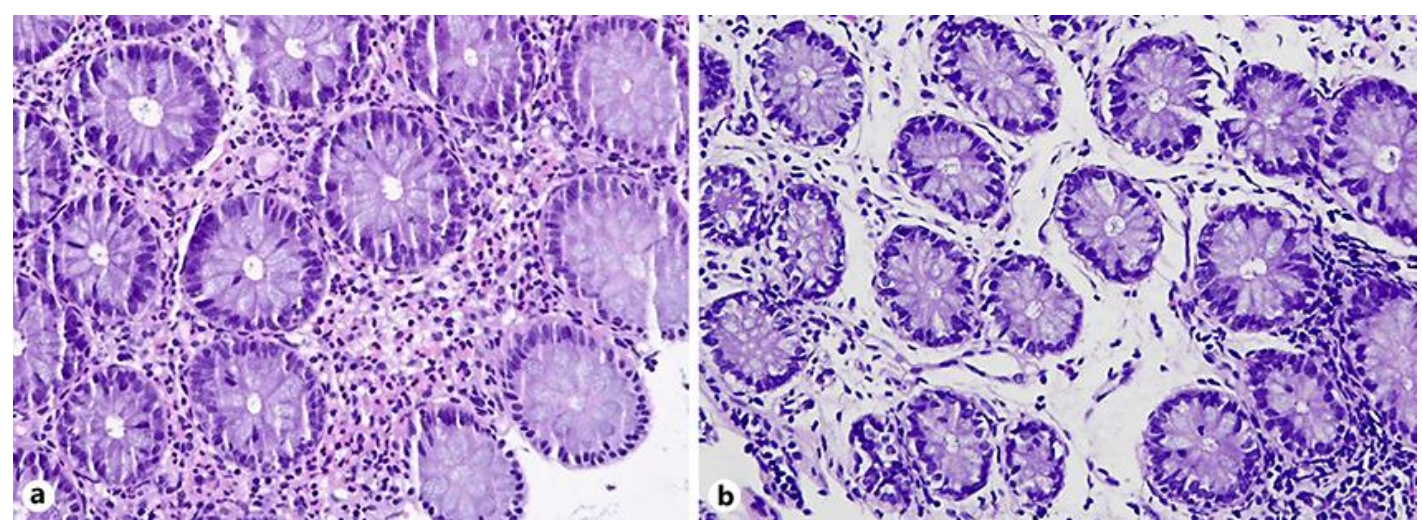

Fig. 1. The colonic biopsies showed a mean number of $>60$ eosinophils/HPF $(\times 400)$ prior to treatment (a) and there was no eosinophil infiltration in colonic mucosa at posttreatment biopsy (b), indicating an improvement of eosinophilic inflammation with the use of combined therapy with montelukast and ketotifen.

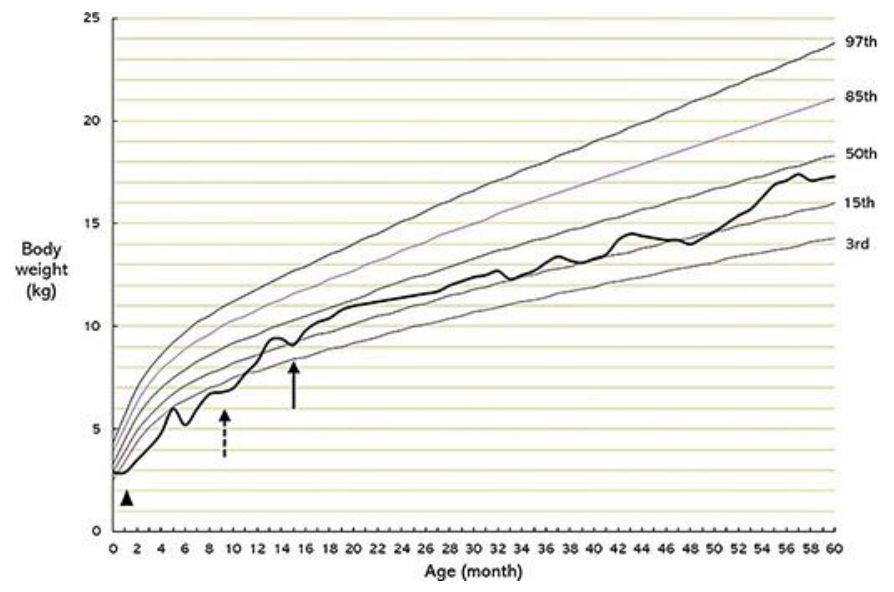

Fig. 2. The growth chart showed growth retardation from visits prior to montelukast and ketotifen therapy (arrowhead). The body weight caught up after adding montelukast and ketotifen therapy (dotted-line arrow). Moreover, the growth curve remained even after the cessation of medications (solid-line arrow).

\section{Karger'}

